\title{
UNA IDENTIDAD ESCOLAR DEFENDIENDO LA ESCUELA PÚBLICA
}

\author{
Linda Soraya Khodr* \\ Instituto de Desarrollo Económico Social, Argentina \\ khodrlinda@gmail.com
}

Recibido: 9/06/2019 Aceptado: 9/12/2019

\section{Resumen}

A partir de la reforma educativa de los 90', la escuela secundaria bonaerense está inmersa en procesos de severas transformaciones que han deteriorado, especialmente, al sector de la educación pública.

En este artículo me propongo indagar y comprender algunos componentes novedosos en las relaciones y prácticas pedagógicas, políticas y sociales en y desde "la escuela", rasgos que emergen en la actualización de los conflictos escolares y extraescolares de la secundaria bonaerense como producto de quiénes han accionado en su "defensa".

Para ello describo y analizo etnográficamente el acto de imposición del nombre Ernesto 'Che' Guevara, a la Escuela de Enseñanza Media N 7 del municipio de Berazategui, Argentina.

Esta nominación fue el resultado de un largo proceso al que yo entendí como el principal medio por el cual se jugó un drama social, es decir, una disputa de poder entre dos bandos: los actores escolares y las autoridades gubernamentales municipales y provinciales; quienes dirimieron durante más de quince años por el control político e ideológico de la institución.

Los actores escolares lograron cerrar a su favor la disputa mediante una performance ritual que mostró una identidad escolar inédita y legitimada.

Palabras clave: Etnografía - Identidad escolar - Performance ritual - Dimensión política - Escuela Pública Secundaria.

\begin{abstract}
Since the education reform of the 1990 the secondary schools of the province of Buenos Aires have been undergoing severe transformations which have deteriorated, in particular, state schools. In this article, I intend to inquire into, and understand, some of the novel components of the pedagogical, political and social relationships and practices of "the school", aspects which emerge within the enactment of school and out-of-school conflicts of the secondary school of Buenos Aires due to those who have acted in its "defense". In order to do this, I ethnographically describe and analyse the ceremony of naming High school Number 7 of the municipality of Berazategui, Argentina, after Ernesto "Che" Guevara. This act of naming was the result of a process which I understood as the main means by which there came to be a social drama, that is, a power struggle between two sides: the school actors and the municipal and provincial governmental authorities, who fought for the political and ideological control over the school for more than fifteen years. The school actors were eventually able to resolve the dispute in their own favour by means of a ritual performance which displayed an unprecedented and legitimized school identity.
\end{abstract}

Keywords: Ethnography - School Identity - Ritual Performance - Political Dimension - State Secondary School.

\section{Introducción}

En Argentina la reforma educativa de los 90' fue parte de la fragmentación y transmutación del Estado y estuvo signada por la irrupción de la política partidaria en la cotidianeidad escolar, dentro de un 
proceso de recesión económica, movilidad social descendente y creciente desconfianza en las autoridades gubernamentales (Milstein, 2009).

En la provincia de Buenos Aires la escuela secundaria está inmersa en procesos de severas transformaciones que han deteriorado, especialmente, la educación pública ${ }^{1}$. En este artículo me propongo indagar y comprender algunos componentes novedosos en las relaciones y prácticas pedagógicas, políticas y sociales en y desde "la escuela", rasgos que emergen en la actualización de los conflictos escolares y extraescolares de la secundaria bonaerense como producto de quiénes han accionado en su defensa. Con ese objetivo describo y analizo el acto de imposición del nombre a una institución, el cual fue el resultado de un largo proceso al que yo entendí como el principal medio por el cual se jugó un drama social (Turner, 1985), es decir, una disputa de poder entre dos bandos: los actores escolares y las autoridades gubernamentales, quienes dirimieron durante más de quince años por el control político e ideológico de la escuela.

El trabajo de campo etnográfico lo realicé en la Escuela de Enseñanza Media $N^{\circ} 7$ (EEM N ${ }^{\circ} 7$ ) de Berazategui, Buenos Aires, Argentina, durante los años 2009-2010 con la colaboración de integrantes de su Centro de Estudiantes (de aquí en adelante $\mathrm{CE}$ ).

En la narración de los sucesos seguiré la estructura procesual de los ritos de pasaje, tal como fueron estudiados por Van Gennep (Turner 1982; Mc Laren 2007; Guber 2009), quien ha observado que los mismos se desarrollan a través de tres fases: separación, transición y reincorporación. Señalo con Turner (1985) el valor que tienen los rituales cuando forman parte de la etapa de cierre de los dramas sociales, ya que pueden ser empleados como medios para alcanzar fines en los procesos dramáticos. Así se convierten en performances, formas estéticas que despliegan su poder creador, crean el sentimiento de communitas en estado liminal, donde es posible resignificar las estructuras de la experiencia grupal. De allí la pertinencia de focalizar en el performance ritual de imposición del nombre Ernesto "Che" Guevara para describir y analizar la transformación de la escuela secundaria, pensándola más allá de los cambios curriculares y de las políticas públicas de las sucesivas reformas educativas. Observando rasgos emergentes, producto de la dinámica conflictiva en las relaciones escuela-gobierno.

\section{Breve reseña histórica}

Institución pública de enseñanza secundaria ubicada en la localidad de Villa España del municipio de Berazategui, a $27 \mathrm{~km}$. al sudeste de la ciudad de Buenos Aires. Fue creada a pedido de los vecinos y cooperadores de la Escuela Primaria $\mathrm{N}^{\circ} 1$, actualmente lindante, comenzando a funcionar en el turno noche en aulas que esta primaria le prestó en marzo de 1990. El edificio propio se construyó por etapas, en una primera con fondos y mano de obra de la propia comunidad educativa, con algunas donaciones de particulares y del municipio. Las otras dos etapas -1994 y 2008-estuvieron a cargo de la provincia de Buenos Aires.

Cuando comencé el trabajo de campo -ciclo lectivo 2009- $\operatorname{los}^{2}$ estudiantes del turno mañana y tarde ${ }^{3}$, unos 680- estaban cursando el plan de estudios Polimodal. En el año 2010, con el lanzamiento en la provincia de Buenos Aires de la Secundaria de la Provincia ${ }^{4}$, parte del alumnado estaba en este nuevo plan de estudios y parte en el viejo. Desde el 2012 todos cursan la Secundaria.

El 8 de octubre de 2009 se desarrolló el acto político-educativo de su nominación oficial como E.E.M. N ${ }^{\circ} 7$ Ernesto 'Che' Guevara, logrando que la Dirección General de Cultura y Educación ${ }^{5}$ legalizara el nombre que la comunidad escolar había elegido en 1997 mediante el voto tanto de los estudiantes; docentes, auxiliares, como así también, de aquellos familiares que quisieron participar; nombre posteriormente refrendado con un plebiscito en el año 2007.

\section{El Centro de Estudiantes, la Comisión de Egresados, directivos y docentes en el contexto escolar}

Las reuniones del CE son semanales y están abiertas, aunque no sean delegados de curso ni integren formalmente la comisión directiva. Suelen participar entre diez a veinticinco estudiantes y comenzar con alguien que dice: vamos haciendo la ronda o che hagan el círculo, además de esta distribución espacial frecuentemente manifestaban su preocupación por tomar decisiones en forma horizontal y por concretar lo decidido "tenemos que movernos con los proyectos, si no los hacemos quedamos mal, no podemos ser igual que los políticos” (Gabriela, 17 años).

\footnotetext{
${ }^{1}$ Sus directivos, docentes y personal auxiliar son contratados por el estado provincial que, a su vez, mantiene los edificios y mobiliarios. Existen también escuelas privadas que reciben subvenciones para pagar porcentajes de los salarios docentes (denominadas públicas de gestión privada) y otras que no reciben subvención alguna del estado.

2 Para hacer ágil la lectura utilizo la escritura convencional, empleando el artículo "los" pero en el mismo se incluye la participación de "las" y "les".

${ }^{3}$ El turno vespertino ofrece la modalidad "Bachillerato de Adultos con orientación en Ciencias Naturales" que cuenta con 270 estudiantes, pero yo centré mi trabajo de campo en el Polimodal-Secundaria, por cuestiones de organización del mismo y la imposibilidad de abarcar una franja horaria tan extensa.

${ }^{4}$ Nivel de carácter obligatorio a partir de la Ley Provincial de Educación $13.688 / 07$. El mismo se compone de dos ciclos: uno básico (ESB) $1^{\circ}, 2^{\circ}$ y $3^{\circ}$ año y otro superior orientado constituido por $4^{\circ}, 5^{\circ}$ y $6^{\circ}$ año.

${ }^{5}$ Es la institución de la provincia de Buenos Aires que con rango de ministerio organiza y supervisa el sistema educativo provincial.
} 
En el tiempo que compartimos me comunicaron que la escuela ya tiene su lugar y prestigio en Berazategui por todo el trabajo realizado a lo largo de su historia: "casi seguro que nosotros fuimos la primera escuela en toda la provincia en trabajar el tema de los derechos humanos, y somos de Berazategui" y, también, "Es muy importante que una escuela se llame Che Guevara". Por ello, sostenían que ahora debían seguir trabajando para conseguir que las autoridades municipales y provinciales reconozcan su derecho a llevar ese nombre oficialmente.

Lolo es el apodo de quien fue presidente del primer CE, estuvo en la escuela desde su apertura en Marzo del'90. Él me comentó la relación especial que tenían con sus profesores y directivos, la cual se afianzó fuera del horario escolar, cuando se reunían a trabajar voluntariamente para construir las primeras aulas propias y, de paso, recrearse:

(...) incluso había veces que no hacía falta convocar, porque era espontáneo. Con nuestros amigos directamente nos juntábamos, el hecho solamente de que estaba la escuela abierta ya nos convocábamos para venir a ayudar, a jugar un poquito al fútbol y compartir con los profesores que venían, por eso fue muy linda esa etapa, muy natural. (Entrevista a Lolo, 10-32010)

Este primer grupo comunitario -estudiantes, docentes, directivos, auxiliares y cooperadorescomienzan un enfrentamiento con las autoridades municipales y provinciales a fin de poder preservar el espacio escolar ante la irrupción política partidaria, que se produjo en el acto de inauguración del edificio escolar propio en 1994, con la presencia en el acto protocolar de militantes partidarios y beneficiarios de planes sociales que eran ajenos a la escuela, pues procedían de otros municipios y venían acompañando a las principales autoridades gubernamentales de la provincia:

(...) Nos vinieron a tapar porque había venido el intendente, el gobernador, toda una comitiva, habían venido con su gente, con su bandera, habían caído con unos micros y nos taparon, pusieron sus banderas adelante. $\mathrm{Y}$ a ese grupo nuestro nos dejaron atrás. Eso después lo hablamos con Osvaldo [director] y le dimos nuestro punto de vista, que lo vimos mal en ese sentido, que no fue nuestra fiesta, (...) que políticamente nos coparon. Entonces acordamos hacer otra fiesta, que fuera de la escuela el 25 de mayo, después nos quedamos en una velada que nos hicieron a los chicos que más trabajábamos. (Lolo, 10-3-10)

La presencia partidaria en una inauguración edilicia fue un hecho inédito para una escuela en Berazategui, y totalmente contrastante con los valores de neutralidad política y de la separación del adentro y afuera escolar tan obsesivamente reforzada en el sistema escolar argentino (Milstein, 2009, p. 174). Esto explica el gran malestar que generó dentro de la escuela este intento de incorporarla al territorio del sector político del gobernador, como observamos, en las palabras de quien era el director:

Nosotros habíamos quedado muy molestos por el acto, porque fue un acto partidario en vez de un acto escolar, donde nos desplazaron, la gente solo quería irse a su casa. Trajeron micros de Almirante Brown, de gente que estaba ahí realmente por necesidad. Si esa gente, hay que decirlo, durante el Duhaldismo ${ }^{6}$ fueron explotadas por sus necesidades (...) entonces quedamos muy molestos, yo hice un discurso duro (Osvaldo, $1^{\circ}$ director, entrevista 1-11-2010)

Entre los profesores que están desde el comienzo he encontrado relatos que dan cuenta del carácter distintivo de esta institución, sobre cómo vivenciaron una clara ruptura con la escuela del período de la dictadura, y de su determinación de realizar la tarea pedagógica del traspaso generacional de la memoria histórica social de ese período trágico del país. Los siguientes fragmentos son de la entrevista a un profesor -que está desde el '93- hecha por un grupo de estudiantes para "Jóvenes y Memoria"?

(...) caíamos en una escuela en la que muchos cuando éramos adolescentes - muchos de nosotros terminamos la secundaria en plena dictadura- nos hubiera gustado tener. $\mathrm{Y}$ esto, reconozco que es muy subjetivo, que era la escuela que a uno le hubiera gustado tener como escuela secundaria. Si uno se pone a pensar en el '95 nosotros hicimos - con Osvaldo como director- creo que fue la primera jornada sobre derechos humanos, y trajimos a la presidenta de "Abuelas de Plaza de Mayo", Estela de Carlotto, y vino Pablo Díaz, que fue el único ${ }^{8}$ sobreviviente de la tristemente célebre "Noche de los lápices", , iy para esa época: pleno '95, Menem y Duhalde! Menem a nivel nacional y Duhalde a nivel provincial, Mussi) ${ }^{10}$ a nivel

\footnotetext{
${ }^{6}$ En referencia a Eduardo A. Duhalde, quien por entonces era el gobernador de la provincia de Buenos Aires, en 1999 pierde en las elecciones presidenciales ante F. de la Rúa y, a raíz de la crisis de diciembre de 2001, es elegido presidente el 2 -1-2002 por la Asamblea Legislativa.

Programa provincial de la Comisión de la Memoria. Para el cual hicieron obras de teatro: en el 2009 sobre la temática de la violencia tanto material como simbólica ejercida sobre los jóvenes, y en el 2010 sobre la historia de la escuela.

8 También sobrevivieron Emilce Moler, Patricia Miranda y Gustavo Calotti.

${ }^{9}$ Se conoce así al secuestro de 10 integrantes de Centros de Estudiantes de la ciudad de La Plata ocurrido el 16/9/76.

De los cuales 6 integran la lista de desaparecidos.

${ }^{10}$ Juan José Mussi por entonces intendente municipal.
} 
municipal. Era medio raro que una escuela se tirara a hacer una cosa así. (...) (2-6-2010profesor)

Así, en esta escuela, fueron realizando prácticas pedagógicas que transmitieron conocimientos que iban a contramano de las políticas de olvido impulsadas desde el gobierno. Los derechos humanos se constituyeron en un problema transversal al cual se abocaron en la escuela, lo cual agudizó el conflicto con las autoridades municipales:

(...) Y nosotros en esa época éramos muy, muy perseguidos y no de una manera muy pintoresca precisamente, nos decían que éramos la escuela "zurda" de Berazategui, de una manera hasta despectiva, y como hoy yo le planteaba a alguno de los chicos a la tarde, nos fueron pasando un montón de facturas con los años (...) Fue la única escuela que no articuló la desastrosa reforma federal del '94, no articulamos con primaria (...) (2-6-2010-profesor).

Desde el comienzo de mi estadía en la escuela distintos adultos de la comunidad escolar me señalaron a Tuti, integrante de la Comisión de Egresados, como un interlocutor ineludible: "tenés que hablar con Tuti que es uno de los que más colabora con la escuela". A él lo vi enseguida en una reunión del CE, a la cual asistió en representación de la Comisión de Egresados, y de ahí en más participó en forma frecuente colaborando en distintas actividades escolares: "El 7 Rock" "11, "La Carrera de Miguel ${ }^{12}$, "El Acto Académico"; "Jóvenes y Memoria" y como orador en el "Acto de imposición del nombre a la escuela".

En el año 2007 el CE y la Comisión de egresados organizaron un reclamo al Consejo Escolar ${ }^{13}$ de Berazategui - junto a otros CE del municipio- por temas edilicios, de becas y alimentación. Fueron a las puertas de esas autoridades con una bandera que decía "La educación del pueblo no se vende se defiende!!!” y, también, aprovecharon para poner con cánticos en la calle el nombre elegido para su escuela. Los consejeros escolares los recibieron y, además, consiguieron las mejoras, pero...

(...) nosotros desde la mirada adulta éramos no sé, unos mocosos que no queríamos tener clase y nos íbamos a hacer lío ahí, a la puerta de Consejo Escolar. (Tuti)

Analizando ese período, Tuti afirma que recibieron ayuda y colaboración de diversos adultos, así, el CE le solicitó al director actual que les justificara la falta a los estudiantes que asistían a la marcha, "ya que es un derecho gremial" y él accedió. También, la relevancia del profesor a cargo de presentar todos los papeles reglamentarios, una y otra vez, para lograr la oficialización del nombre. Así, fueron ponderando durante este proceso de prácticas políticas las distintas posibilidades de acción según los roles que cada uno tiene dentro de la comunidad de práctica escolar, por ejemplo, los estudiantes pintaron el nombre en el frente, sobre el pórtico escolar años antes de ser aprobado por la Dirección General Cultura y Educación, en una actividad del CE un día feriado:

(...) porque, por ahí hay cosas que los profesores, en su condición de profesores no pueden hacer tanto, como un día treparse a una escalera y poner Ernesto Che Guevara porque por ahí molesta, políticamente no les conviene mucho; o el director, no puede un día aparecer con un aerosol. Pero lo bueno es que ellos siempre dieron el marco para poder hacerlo (Tuti).

\section{El ritual de nominación escolar}

\section{Los preparativos para el "Gran Acto", la fase de separación}

La Dirección General de Cultura y Educación estableció, por la resolución 4726/08, que durante el 2008 comenzaría un proceso de imposición de nombres a todas las instituciones educativas de la provincia. Sin embargo, a comienzos del ciclo lectivo 2009 el nombre de la escuela continuaba "encajonado" ${ }^{14}$. El malestar había crecido a partir de aquella resolución, ya que la misma proporcionaba un marco legal para la oficialización del nombre, pero en la práctica, el Director General de Escuelas no convalidaba con su firma el expediente que la escuela había ingresado, nuevamente, en el 2007.

La noticia de la aprobación oficial del nombre llegó a la escuela en agosto del 2009 y decidieron realizar el acto el día 8 de octubre, en coincidencia con la fecha de la captura de Ernesto Guevara en

\footnotetext{
${ }^{11}$ Festival de música y talleres de arte que tiene a los estudiantes y egresados como protagonistas.

${ }^{12}$ Actividad abierta a toda la sociedad, que se realiza desde el 2005 y es sumamente importante en la construcción de la identidad escolar, porque en ella se homenajea a un vecino detenido- desaparecido en 1978 por el terrorismo de estado. Esta preservación de Miguel Sánchez en la memoria social del barrio comenzó en 1996 y se prolongó en una disputa con las autoridades municipales por colocar su nombre a una calle adyacente a la escuela, lo cual ocurrió en 2001.

${ }^{13}$ Órgano político descentralizado de la Dirección General de Cultura y Educación, Los candidatos a consejeros escolares están en la misma boleta partidaria que los candidatos a concejales distritales y a intendente municipal. Su función es administrar las partidas presupuestarias que le envía la DGCyE para la infraestructura escolar (mantenimiento, ampliaciones, limpieza), el servicio alimentario escolar y se encargan de la designación de auxiliares (portero/as y cocinera/os).

${ }^{14}$ Término que las/los actores escolares utilizaban haciendo referencia a que las autoridades educativas municipales y provinciales tenían frenado el expediente.
} 
territorio boliviano. Fundamentaron la elección de esa fecha porque "muere el hombre y surge el mito del idealista eternamente joven". (Director en funciones)

En el salón que funcionaba en forma compartida la preceptoría y la sala de profesores se podía leer colocado sobre el armario, lugar muy visible, el anuncio del evento en una hoja blanca tamaño carta que en letras negras gruesas decía "Preceptores el día 8 de octubre - 12 horas LA ESCUELA TIENE NOMBRE! ERNESTO "CHE" GUEVARA. GRAN ACTO! ESTAN TODOS INVITADOS."

Dos días antes hicieron un paréntesis en su rutina, sólo en esta escuela del municipio no se dictaron las clases. Utilizaron el tiempo para comenzar con los preparativos del espacio escolar para el "Gran Acto". A diferencia de la preparación de otros actos escolares éste implicó la suspensión total de las clases y, tanto los estudiantes, docentes como auxiliares realizaron diversas tareas de: pintura de las aulas y pasillos; limpieza de pupitres; cortar el pasto y plantar flores; aprontar y decorar el SUM ${ }^{15}$; un grupo de estudiantes coordinados por una profesora puso mucha dedicación en confeccionar, en papel afiche, las banderas de todos los países latinoamericanos para la preparación del escenario. El día previo al acto escolar no se dictaban clases en todo el distrito por ser fecha de "jornada institucional"16, ésta se realizó en el turno mañana dando lugar a que voluntarios, tanto jóvenes como adultos, continuaran reorganizando el espacio escolar para la celebración del acto. Experimentaron un tiempo distinto al habitual, mediante las actividades del armado del escenario en el patio y del montaje de dos instalaciones en el SUM: 1- sobre la pared lateral derecha la muestra fotográfica "Locas y atrevidas, Madres"17 y 2- en la esquina izquierda elementos recordatorios de todas las ediciones de La Carrera de Miguel. Así establecieron un tiempo distinto al cotidiano, un fuera de tiempo que marcó el inicio del ritual de paso a su nueva posición social mediante una "separación" con respecto a las otras escuelas del municipio.

\section{La fase de transición: un inicio inesperado para un acto escolar: La performance de un nuevo vínculo intergeneracional}

Para quienes asistimos al acto de nominación la cualidad especial del tiempo, que ese día y allí estábamos vivenciando, estuvo señalada por un cambio del habitual inicio de las ceremonias escolares que comienzan con el ingreso de los abanderados y sus escoltas portando la bandera nacional y provincial, ante la audiencia que aplaude de pie y con los estudiantes formados por curso. En forma contrastante, el "Gran Acto escolar" comenzó a las 12 horas con un desplazamiento de todos los presentes -solicitado por la profesora Ana quien hizo la locución junto con el profesor Martín- desde la galería de ingreso y el patio hacia el SUM para, una vez allí reunidos sin un lugar pre establecido según los roles y status, sino libremente dispuestos, compartir un video institucional que contiene la localización, la historia, los proyectos educativos y opiniones sólo de los estudiantes, es decir, no contiene apreciaciones sobre la escuela de los adultos que la habitan. Video que fue producido especialmente para este acontecimiento. Con aquella forma comenzó el acto, con todos los presentes trasladándonos desde los distintos espacios escolares con el objetivo de reunirnos para escuchar y ver, proyectados sobre la pared del SUM, a los únicos protagonistas de este video: los estudiantes, la mayoría integrantes del CE, quienes aparecían filmados en distintas locaciones de la escuela trasmitiendo con sus palabras la historia escolar, a la cual la enmarcaron en una dinámica social de "lucha de la comunidad". (Milton, CE)

En el video presentaron los proyectos institucionales con material fotográfico y fílmico de archivo, apareciendo en sobreimpresos las palabras que estudiantes iban diciendo y que consideraron más significativas de la identidad escolar, así destacaron: por qué y cómo se construyó la escuela: "1990- Villa España, no había escuelas Medias"; "Viajar para estudiar"; "Escuela primaria 1 cede tres salones"; "defensa de la Escuela pública- gratuita"; "cooperadora- espacio edifico propio"; "1993-Esfuerzo comunidad- más aulas"; "2007- Marchas falta de espacio"; b-sus proyectos pedagógicos distintivos: "defensa de los Derechos Humanos"; "recuperación de la Memoria"; "Jornada de Educación Popular"; "charlas de Derechos Humanos"; "Apoyo a las Luchas Sociales, Carpa Blanca, Subestación Rigolleau"; "Carrera de Miguel"; "7 Rock"; "campamentos educativos"; "Jóvenes y Memoria" y c-las relaciones interpersonales: "Escuela- Expresarte"; "escuchar la voz del otro"; "valor a lo que piensan los alumnos"; "Escuela única"; "para los alumnos y con los alumnos"; "oportunidad de hablar"; "falta compromiso de los pibes"; "faltan profesores, escuela pública"; "siempre te escuchan"; "recordar que todo se puede".

En sus observaciones sobre la escuela, en el video, los estudiantes señalaron como primordial:

(...) elegí la escuela, principalmente, porque me la recomendaron en muchas partes, y porque sé que es una escuela que le dan mucho valor a lo que piensan los alumnos y lo que ellos quieren hacer, es muy importante eso. (Sofía, CE)

(...) es una escuela única, pasé por varias escuelas y ésta es la que más me convenció, y es la que veo que en realidad se hacen cosas para los alumnos y con los alumnos. (Ignacio, CE)

(...) el problema de las becas o el comedor es en todas las escuelas públicas, pero este es un caso muy especial porque siempre que vas a hablar con los directivos o los preceptores, siempre te escuchan y eso es re importante, porque uno no siente que cuando luchas por algo te quieren hacer que agaches la cabeza y no sigas. Pero acá siempre lo que te tratan de recordar es que

\footnotetext{
${ }^{15}$ Abreviatura de salón de usos múltiples.

${ }^{16}$ Se trata de una capacitación en servicio que se realiza en todos los niveles en fechas que establece la DGCyE

${ }^{17}$ Del fotógrafo berazateguense J.D. Vera, la cual se mantuvo hasta finalizada La Carrera de Miguel 2009.
} 
sigas y que sigas, y que todo se puede. (...) y también es muy importante que una escuela se llame Ernesto Che Guevara, es muy importante. (Gaby, CE)

Entre las opiniones que vertieron, también, hubo críticas:

Bueno por ahí lo que falta es un poco más de compromiso de los pibes para con el colegio, por ahí que los alumnos comiencen a querer más al colegio y empiecen a darse cuenta de lo que es este colegio, porque en realidad no somos muchos los que lo apreciamos y hacemos cosas. Eso, por ahí, es de lo único que nos podemos quejar porque en general es una escuela bastante buena. (Ignacio, CE)

(...) la falta de los profesores y cosas así que, pero bueno en la mayoría de las escuelas públicas (Eugenia, CE)

Transmitieron la historia de la escuela, pero de un modo inesperado e inédito para una institución educativa, donde habitualmente se resalta la dimensión pedagógica ocultando la política. Por el contrario, aquí se hizo visible que los proyectos pedagógicos emergieron de circunstancias sociales adversas y de pujas políticas. Además, los portavoces de la institución no son los directivos o los profesores sino los adolescentes que participan del centro de estudiantes, muchos de ellos habían participado dos años antes de la marcha y reclamo al Consejo Escolar, por lo tanto era factible que las autoridades educativas municipales, presentes en este acto, los catalogaran como "los revoltosos". Sin embargo, las autoridades escolares deciden otorgarles el protagonismo en la transmisión de la historia.

Al concluir el video se escucharon fuertes aplausos y se percibía un clima emocional con distintos matices e intensidades en los modos de aplaudir; en los rostros que sonreían o no; los que necesitaban comentar con otros lo que habían visto y escuchado; algunas felicitaciones con abrazos y otras más formales. Pasados unos minutos la profesora locutora solicitó por micrófono que nos trasladáramos al patio para continuar allí la ceremonia. Con movimientos espaciales realizados hacia y desde el SUM corporizan el transcurso de "la etapa de transición", el umbral que mantiene aún a los sujetos del ritual -en este caso a la comunidad escolar- en un estado indefinido o área ambigua pero que ya contiene los atributos más cruciales de su identidad que aún es profana, es decir, todavía no ha alcanzado la importancia de lo sagrado que pueden adquirir las instituciones seculares.

\section{La etapa ritual de reintegración}

Un nuevo desplazamiento espacial nos colocó a todos los presentes frente al escenario construido para dar marco a los discursos que "reintegran" a la escuela a su nuevo estatus social y que, mediante la legitimación de su identidad, dio un cierre al drama social. Aunque no fue expresamente indicado, cuando llegamos al patio para continuar con el acto, los lugares cercanos al escenario fueron ocupados siguiendo el protocolo, es decir, en las primeras filas de sillas se sentaron las autoridades: Inspector Jefe Regional, Inspector Jefe Distrital, Secretaria de Inspección, Inspectores de diversas áreas, Consejeros Escolares, Diputados Provinciales, el Director de la Escuela, miembros de la Embajada de Cuba, dirigentes gremiales y el hermano de Ernesto Guevara. La concurrencia restante ocupó las filas posteriores y muchos quedamos de pie.

\subsection{Un escenario Latinoamericano, el símbolo dominante y sus expansiones metafóricas}

La producción del escenario requiere de nuestra mayor atención, ya que allí se ubicó el símbolo dominante del ritual, la Imagen del Che, que se enlazó en modo primordial con la bandera nacional, conjunción muy potente ya que ésta es símbolo nuclear en la escuela argentina. En el borde superior del telón colocaron todas las banderas de América Latina, las cuales ocupaban el ancho total del escenario, y sobre el paño rojo una foto del rostro del "Che". En esta imagen, que han seleccionado para el acto, llevaba puesta su conocida boina con la estrella y la dirección de la mirada es hacia abajo, lugar donde los actores escolares emplazaron la bandera Argentina, quedando ambos símbolos -la foto del Che y la bandera nacional- en línea perpendicular con el centro del piso del escenario. 


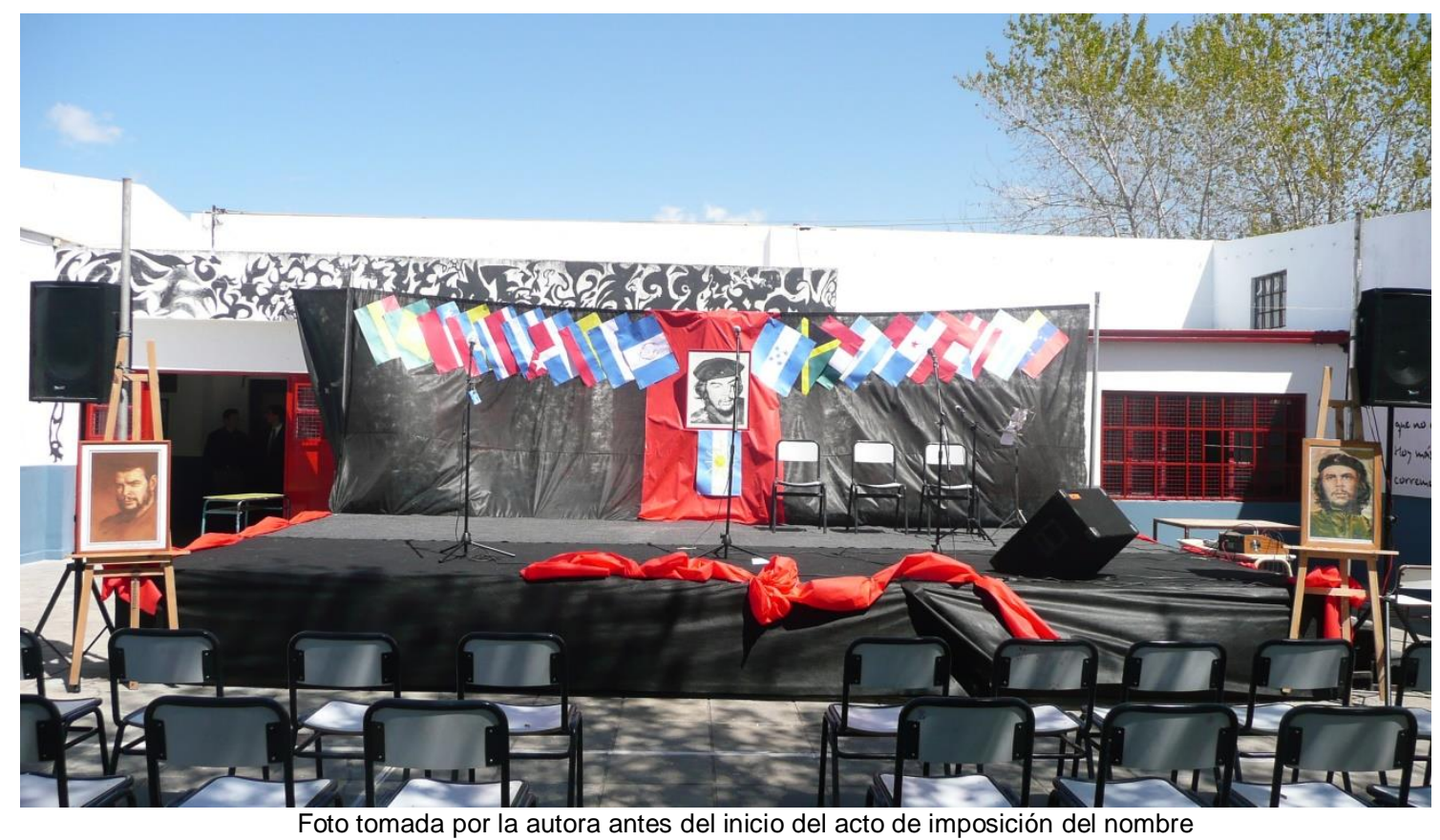

En el suelo, plano espacial destinado para la ubicación de la audiencia, y mirando hacia ésta, colocaron a ambos costados del escenario atriles con retratos: a la izquierda Ernesto Guevara, el "hombre" y, a la derecha la mítica fotografía tomada por A. Korda en 1960, quien la tituló Guerrillero Heroico ${ }^{18}$.

En la producción de este escenario hay un acto performativo sobre cuál es el espacio en que inscriben esta nueva identidad escolar y sobre cómo la significan; simbolismo que luego, durante el desarrollo de la fase de reintegración se reforzó con el lenguaje, tanto de las glosas como por lo expresado por los oradores. Reafirmándolo, en una reunión programada para ejercer la reflexividad en forma compartida con protagonistas estudiantiles, ellos sostuvieron que en realidad ahora comienza una batalla cultural.

...me parece que el Che Guevara tiene que estar presente ahí, constantemente, la idea del hombre nuevo tiene que ser un poco así el horizonte que vaya guiando el laburo en la Media 7 y también más allá, yo no quiero que la Media 7 sea una burbuja sino que sea un ejemplo que se pueda ir, no imitando pero viendo [sonriendo] socializando. (Tuti, 9-01-2012)

En la construcción del escenario, espacio en el cual se realizó el pasaje a su nuevo estatus social, se trazó simbólicamente un recorrido deseado que iba de una punta a la otra del escenario y que, en su centro, mantenía la mirada atenta del rebelde como garantía de su realización. Inmersa en el territorio latinoamericano, la rebeldía sobre el símbolo patrio de los argentinos representa las confrontaciones realizadas por el pueblo durante las tres últimas décadas, y es un atributo necesario de mantener en tiempos en que la educación pública continúa profundamente deteriorada. De esta forma se posibilita que el nombre no sea sólo un cartel sino que implique un cambio desde la posición marginal, de quien está pujando desde afuera de lo establecido con el objetivo de cambiar los márgenes de lo posible en la sociedad -posición típica del guerrillero representada en el atril de la derecha- a otra posición nueva pero aceptada, y así poder establecerse como una persona -social en este caso- integrante de una sociedad más justa: el hombre nuevo, simbolizado en el atril izquierdo.

La escuela fue la forjadora del sentido de pertenencia a la nación argentina. Los actos escolares, a través de su símbolo dominante: la bandera -y las relaciones establecidas con otros símbolos- fueron la principal tecnología para construir esa comunidad imaginada, aplanando las diferencias étnicas, sociales, religiosas, económicas, políticas de quienes habitan el territorio nacional (Blázquez, 1997; Guillén, 2008). La presencia de una bandera ceremonial de los pueblos originarios (veremos abajo) junto a la bandera nacional es significativa del inicio de un proceso de valoración de las diferencias y de la comprensión de las relaciones de dominación que propiciaron y propician la invisibilidad de estos pueblos.

18 "El famoso retrato de Ernesto Guevara que se difundió mundialmente casi como una marca registrada. Icono indudable de la revolución, la romántica imagen del Che como héroe revolucionario, alimentó los sueños de toda una generación de jóvenes por un mundo más justo, más equitativo" (Ernesto Mallo, catálogo de la muestra fotográfica "Cuba, la revolución y la Habana contemporánea" Palais de Glace - Palacio Nacional de Las Artes, 8 mayo- 1 de junio de 2008. 
A través de su acción ritual la escuela pública dio origen en el siglo XX al paradigma raíz ${ }^{19}$ "la escuela pública nos iguala y garantiza el ascenso social", en el cambio de siglo la desestructuración estatal y la crisis social-económica- política desarrolló un proceso social altamente conflictivo, con pauperización de la clase media y extrema pobreza de los sectores populares. Es en este contexto que las escuelas públicas dejan ver, como nunca antes, el carácter político de su espacio con la presencia de distintos sectores pujando por sumarlas a su territorio, vaciándolas de recursos materiales y de prestigio.

En este escenario se simbolizó la rebeldía de la nación argentina o, más precisamente, de los sectores populares que ejercen su agencia política para restablecer el equilibrio del poder a su favor y, mediante su acción simbólica buscan expandir metafóricamente "la defensa de la escuela pública".

\subsection{La emoción convalidando la posición social de la escuela}

Subieron al escenario los dos docentes designados para la locución. Comenzó Ana diciendo que "se encontraban presentes para acompañar a la escuela en este día tan especial", e inició la lectura de la nómina de las principales autoridades, primero el cargo y luego el nombre del funcionario/a que lo ocupaba, todos ellos ordenados de mayor a menor jerarquía, tal cual establece el protocolo, luego mencionó sólo por el cargo a los funcionarios intermedios y concluyó la nómina de presentes con "autoridades escolares, docentes, graduados, padres y alumnos. Para todos pedimos un gran aplauso". Sin embargo, la locutora/profesora ex profeso saltea una regla protocolar nombrando a un funcionario ausente, de esta forma en su acto de habla deja marcado el no acompañamiento del intendente municipal, una primera huella del conflicto social que allí comenzaba a saldarse favorablemente para el grupo escolar.

Luego de los primeros aplausos, que se extendieron durante doce segundos, Ana destacó que se hallaban presentes como organización, acompañándolos, el Encuentro por la Memoria, la Verdad y la Justicia de Berazategui, luego mencionó también a cuatro escuelas vecinas -entre ellas la privada- y solicitó "un aplauso también para ellos", el cual duró diecisiete segundos.

En el "Gran Acto" tuvieron un canal de comunicación que dio curso al deseo de transmitir su experiencia y establecer sentido, tal como observamos en las siguientes glosas que habían preparado para ese momento tan esperado:

Si algo nos ha caracterizado es que nos cuesta un poco entrar en los moldes impuestos y no es nuestra intención cometer desprolijidades, pero no queremos perder de vista lo que este logro significa para nosotros. Es un día de mucha alegría, de festejo y queremos compartirlo con todos, respetando sobretodo nuestra idiosincrasia y más allá de las formalidades que el acto requiere, por eso nuestra primera intención es empezar de esta manera. (Ana, locutora/profesora)

Inmediatamente el otro locutor, profesor Martín, dice-: "Bienvenidos todos a Escuela Ernesto Che Guevara”, la voz de Martín sonó firme, aunque emocionada cuando remarcó la pronunciación de Ernesto Che Guevara, enseguida él bajó la mirada intentando contener la emoción que, al no hablar, asomaba en sus ojos. Casi superponiéndose con la última silaba por él pronunciada, de entre los presentes surge un "Bravooo", más bravos y los aplausos suenan fortísimos y muy prolongados; se extendieron durante veintiséis segundos.

Pasado ese éxtasis, el locutor continúa señalando a toda la audiencia que el grupo escolar ha ganado una larga disputa y que la posición social que, recién ahora, es reconocida conserva todos los atributos de identidad que han desarrollado durante esa lucha:

Este logro de hoy es el fruto de una lucha ardua. Esta lucha se ha gestado en la desidia nada casual de los despachos burocráticos que han dilatado por quince años la oficialización de un nombre democráticamente elegido por esta comunidad educativa. Muchas veces nos hemos preguntado: no hubiera sido más fácil aceptar un nombre que refiera a moderados valores conservadores. Pero somos, de alguna manera, esclavos de nuestras convicciones y, finalmente, el camino más largo hoy nos premia con esta felicidad. Siempre [pronunciada con énfasis] hemos tenido identidad, hoy nos entregan el documento. (Martín, locutor/profesor)

Presentaron a quienes estaban presentes "acompañando a la escuela", marcando explícitamente tanto la diferencia con el grupo opositor en el gobierno como "el arduo" proceso que finalmente concluyó favorable a la escuela. En la comunicación entre los locutores y gran parte de la audiencia se generó un espacio político que permitió a ésta última pronunciarse por el grupo escolar, tal como se observó en el

\footnotetext{
${ }^{19}$ Estos "(...) pueden apreciarse en conductas que parecen ser elegidas libremente pero que se resuelven a largo plazo en un patrón total. Trascienden lo cognitivo y aún de lo moral al terreno existencial, y al hacerlo expresan mediante la alusión, la simplicidad y la metáfora. Alcanzan actitudes vitales irreductibles, pasando por debajo de la comprensión consciente hacia un asidero confiable que el individuo siente como asuntos literalmente de vida o muerte. (...) surgen en las crisis de la vida, tanto individuales como de grupo, institucionalizados u obligados por eventos impredecibles. No se puede escapar de su presencia o de sus consecuencias" (Turner en Mc Laren, P 2007, p.25-26).
} 
gesto de aplaudir que fue incrementándose tanto en duración como en la intensidad de los movimientos, al que algunos necesitaron añadir palabras, en tanto:

La acción de aplaudir es invariablemente una exposición de filiación que, en el contexto del discurso político expresa apoyo o aprobación respecto de las afirmaciones que continúan (Heritage y Greatbatch en Spivak L'Hoste 2010, p.134)

Luego de los aplausos, con su identidad ya convalidada, la locutora informó a los presentes que: "para compartir este acto hacen su ingreso las banderas de ceremonia nacional, provincial y de los pueblos originarios", cabe señalar que esta última no está habilitada por el protocolo escolar ni por los usos y costumbres escolares. Hecho que se interpreta tanto por el escenario donde inscriben su territorio como por los lazos que, en jornadas de aprendizajes en Derechos Humanos, fueron estableciendo con distintas comunidades y se expresaron en la presencia de Pablo Quibal representando a los pueblos originarios.

En la conformación de la lista de oradores comprobamos tanto la agencia política de los estudiantes -otorgándole la misma cantidad de oradores que al estatus directivo- como los vínculos con la esfera social ampliada al haber asignado un lugar para el Secretario General de la Central de los Trabajadores de la Argentina: Hugo Yasky; otro a Ricardo Napurí, revolucionario compañero del Che; la Secretaria de Prensa de la Embajada de Cuba: Zulan Popa y al hermano de E. Guevara: Juan Martín Guevara.

En este cierre, el grupo escolar sale fortalecido porque logra imponer como orden legítimo su división del mundo social marcando las diferencias con el grupo antagónico, grupo que desiste de utilizar la palabra para establecer su propia clasificación, de modo tal que el grupo escolar logra un favorable reequilibrio del poder político en la esfera social amplia.

Estás dinámicas de poder se objetivaron en los discursos:

Director fundador, primer orador:

(...) corresponde hacer esta política, porque es la política de la liberación, no la política de la esclavitud, de callarse la boca" [aplausos] Antes de concluir su discurso vuelve a mencionar implícitamente a un integrante del grupo opositor: (...) estoy demasiado emocionado y a veces demasiado caliente cuando veo algunas cosas y caras. [en referencia al inspector jefe distrital, en la grabación escucho risas de los profesores y preceptores ubicados al costado del escenario].

\section{Director vigente, fue el último orador}

(...) a las autoridades que les toca compartir con nosotros espacios, algunas veces en la misma vereda, otras veces en la vereda de enfrente, definitivamente de enfrente. (...)

\section{Tuti, en representación del Centro de Graduados:}

(...) venimos recorriendo un camino desde hace años, algunos como profesores, otros nos tocó en su momento como estudiantes y muchos, también, después seguimos como graduados de este colegio, como es en mi caso y el caso de muchos compañeros más míos, que a pesar de haberse graduado de este colegio siguieron, continuaron apoyando la movida desde el colegio y sumando su granito de arena"(...) Es muy emotivo porque Ernesto Che Guevara no es solamente un nombre, una forma...es un significado....un proceso de lucha por una identidad autónoma.

Lautaro, quien llevó escrito un discurso que firmaron "Centro de Estudiantes de Media 7, hoy más que nunca, como siempre en realidad: Ernesto Che Guevara". A continuación, transcribo partes que reflejan el sentido que el CE le otorgan al nombre elegido, y señalan como élite dominante, a los oponentes, algunas autoridades presentes allí:

(...) Es tiempo del hombre nuevo, el que trabaja sólo por el incentivo moral. (...) Nos sentimos orgullosos del papel que cumple esta escuela en la revalorización de la figura de Guevara, en la discusión en torno a su acción política y a su papel en la historia nacional e iberoamericana. Estamos orgullosos de que la escuela haya sostenido el nombre que eligieron los estudiantes, los profesores y toda la comunidad de Media $^{7}(.$.$) Sabemos que la tarea no es fácil, que colocar$ al Che en su merecido lugar de prócer latinoamericano llevará a la discusión con las voces que responden a las élites con que el mismo Che se enfrentó, que nos enfrentaremos contra todo el aparato cultural que quiere desligar al Che de nuestro pasado y de nuestro presente. Sabemos que la tarea de defender lo conquistado e ir por más no es fácil, nunca lo fue, pero parafraseando al Che Guevara con una idea que marcó mucho la carrera del centro de estudiantes "Si el presente es lucha, el futuro es nuestro". 
Es importante señalar la recepción de estos discursos entre los oradores invitados. El Secretario General de la CTA, H. Yasky, puso a la escuela como ejemplo de defensa de la escuela pública:

(...) se defiende todos los días construyendo esto que Uds. están construyendo, que es pensamiento crítico, que es compromiso con el cambio solidario de esta sociedad (...) párrafo aparte para estos chicos del centro de estudiantes, me llenan de orgullo hablando de por qué elegían el nombre(..) y escuchar a un chico que diga que va a extrañar la escuela (...) creo que el cambio va a venir cuando escuelas como estas sean la norma, sean la mayoría (..).

\section{J.M. Guevara, hermano del Che, rescató que}

(...) tantos chicos de 15 años empiecen a buscar quien es el Che, que no sea sólo una remera o un tatuaje sino quién era, qué hizo (...) y que piensen qué es lo que falta por hacer (...) porque si esta escuela se llama "Che" Guevara, y si en tantos lugares hay "Che" Guevara, es porque faltan cosas por hacer sino sería un héroe más, un recuerdo más, sin embargo no es así, está presente. (...)

\section{Consideraciones sobre este ritual}

La descripción etnográfica, de los preparativos y del acto de imposición de su nombre, permite comprender que no fue un típico acto escolar de características pseudoliminales ${ }^{20} \mathrm{o}$ un acto rutinario generador de resistencia estudiantil (Bláquez 1997; Guillén 2008; Mc Laren 2007) sino que, este acto escolar, podemos entenderlo como "un ritual de pasaje", por el cual "la escuela" -y los distintos actores sociales que la conforman- salen de una posición social marginal y son reconocidos con todos sus atributos de identidad por quienes estaban entablados en una contienda política de larga data que allí, mediante el mismo, quedó saldada.

La etapa final del drama social comenzó a desarrollarse a partir de la noticia de la aceptación oficial del nombre de la escuela, y en este punto debemos considerar con Turner (1982; 1985) que los cierres son siempre provisorios e implican poder comunicar a otros la experiencia vivida. Es en este sentido que el acto de nominación se constituyó en una performance ${ }^{21}$ ritual, siendo posible a través de ella analizar los rasgos identitarios que durante el proceso dramático ha adquirido esta comunidad escolar. En la transición se puso en escena el video institucional, donde observamos que su rasgo esencial está basado en una modificación de la tradicional relación social, de imposición vertical, establecida entre los diferentes estatus y roles que interaccionan en el espacio escolar. Así, en el performance, afirman que en su espacio escolar las relaciones entre generaciones se desarrollan en una simetría ética que está habilitada por la incorporación consciente de la dimensión política a la dinámica escolar, que extiende su accionar a las problemáticas histórico-sociales expresadas en los proyectos especiales, como La Carrera de Miguel, manteniendo en la memoria comunitaria a los detenidosdesaparecidos.

La lógica de la acción social que he descripto va más allá, sin dudas, de obtener legalidad burocrática para el nombre escogido, es mucho más compleja. A través de la aprobación oficial - o nodel nombre, se jugaba cuál de los dos grupos en disputa lograría adquirir mayor prestigio social y, especialmente, poder para el control del territorio escolar.

Es durante y mediante el espacio de experiencia dramática que la comunidad de práctica de esta escuela fue forjando su identidad, espacio donde la participación social de sus integrantes tenía por fin acrecentar poder para evitar la intromisión política partidaria, de modo tal de lograr fijar en forma autónoma sus políticas pedagógicas. Esta construcción identitaria entramada en un proceso conflictivo generó canales de participación para sus integrantes -de los distintos status-, quienes fueron adquiriendo saberes políticos que emplearon, tanto en la puja con el grupo opositor como en la coparticipación con otros grupos sociales, con el objetivo de modificar un contexto sumamente adverso.

La elección de la denominación Ernesto "Che" Guevara para su identidad social les permitió confrontar desde el medio simbólico, alzando el nombre de una figura liminal poderosamente vinculada a la rebeldía y a los procesos de cambio a favor de los sectores más desposeídos. Al mismo tiempo este nombre visibiliza y reivindica la dimensión política de la escuela, lo cual implica un cambio importante en un sistema educativo que se forjó sobre el mito de la neutralidad política, mito que en el ritual fue totalmente refutado. Primordialmente porque mostró un cambio en el "status quo ante", con una modificación en el equilibrio de las relaciones de poder entre los actores escolares y las autoridades gubernamentales.

\footnotetext{
${ }^{20}$ Donde sólo se refuerza la estructura social dominante, lo que Turner denomina "el modo indicativo" el deber ser de lo social.

${ }^{21}$ Esta palabra deriva del francés antiguo parfounir, que significa "completar o "llevar a cabo enteramente" entonces allí, en el performance, se completa la unidad de la experiencia vivida. A través de ella se trae el pasado al presente, poniéndolos en relación, con el objetivo de establecer y comunicar su significado a otros de manera tal que, tanto por el lenguaje como por otros medios puestos en escena, les sea inteligible. (Turner, 1982, p.13)
} 
REVISTA DE LA ESCUELA DE CIENCIAS DE LA EdUCACIÓN, AÑo 16, NRO. 15, VOL. 1, ENERO A JUNIO DE 2020. PÁGINAS 10-20. ISSN 2362-3349 (EN LÍNEA). UNA IDENTIDAD ESCOLAR DEFENDIENDO LA ESCUELA PÚBLICA. LINDA SORAYA KHODR.

\section{Referencias bibliográficas}

Blázquez, G. (1997). Narraciones y performances: un estudio de los actos escolares. 2018, junio 21, de Naya. org.ar. Recuperado de Http://www.naya.org.ar/congresos/contenido/laplata/LP4/27.htm

Guber, R. (2009). De chicos a Veteranos: Nación y memorias de la Guerra de Malvinas. La Plata, Argentina: Al Margen.

Guillén, C. (2008) Los rituales escolares en las escuelas públicas polimodales argentinas. AVÁ Revista de Antropología, 12, Pp.137-154. Julio 2008.

Mc Laren, P. (2007). La escuela como un performance ritual. Hacia una economía política de los símbolos y gestos educativos. México, DF: Siglo XXI editores.

Milstein, D. (2009). La Nación en la escuela. Viejas y nuevas tensiones políticas. Buenos Aires, Argentina: Miño y Dávila.

Spivak L'Hoste, A. (2010). El Balseiro: memoria y emotividad en una institución científica argentina. La Plata, Argentina: Al Margen.

Turner, V. (1985). Dramas, Fields, and Metaphors. Symbolic Action in Human Society. Ithaca, EEUU: Cornell University Press.

-(1982). From Ritual to Theatre. The Human Seriousness of Play. New York,EEUU: PAJ Publications. 